\title{
UMA PROPOSTA DE MAPEAMENTO DE PROCESSOS PARA UMA EMPRESA DE VENDAS EM CONSTRUÇÃO CIVIL
}

\author{
Joanna Pais Ferreira Pinto \\ Engenheira de Produção pelo Centro Federal Tecnológico Celso Suckow da Fonseca \\ (CEFET-RJ), Rio de Janeiro, RJ, Brasil \\ joannapaisfp@gmail.com \\ José Luiz Fernandes \\ Pós-doutor em Engenharia Nuclear pela Universidade Federal do Rio de Janeiro (UFRJ), Professor do \\ Departamento de Engenharia de Produção CFET-RJ, Rio de Janeiro, RJ, Brasil \\ jluizfernandes@gmail.com
}

\begin{abstract}
RESUMO
As diversas mudanças políticas e econômicas marcadas nos últimos anos no Brasil, influenciaram de forma muito negativa no setor da construção civil. Neste cenário surge necessidade da aplicação das melhores práticas de gestão nas empresas. O mapeamento de processos BPMN se destaca auxiliando na redução de custos e aumento da produtividade operacional. Neste trabalho, o conceito foi aplicado em uma empresa de distribuição de material de construção civil através dos conhecimentos teóricos vindos das literaturas e dos conhecimentos práticos obtidos por entrevistas com os colaboradores e indicadores de sua base de dados. O estudo de caso identificou soluções capazes de otimizar o trabalho operacional e auxiliar no planejamento estratégico a longo prazo da empresa, características fundamentais para melhorias nos resultados da organização.
\end{abstract}

Palavras-chave: Mapeamento de Processo. Construção Civil. Melhoria da Produtividade

\section{A PROCESS FLOW ANALYSIS IN A SALES CONSTRUCTION COMPANY}

\begin{abstract}
The political and economic changes that happened recent years in Brazil have a strong negative influence in the construction sector. In this scenario arises the need of applying the best management practices in companies. The BPMN Business process model stands out by helping to reduce costs and increase operational productivity. In this study, this concept was applied in a construction distribution company through the theoretical knowledge coming from the literature and the practical knowledge obtained through interviews with workers and indicators from its database. The conclusion identified solutions capable of optimize operational work and assist the long-term strategic plan of the company, fundamental characteristics for improvements in the organization's results.
\end{abstract}

Keywords: Process Model. Construction. Productivity Improvement

\section{INTRODUÇÃO}

Tendo como partida o mercado da construção civil e, considerando o cenário atual no Brasil, que se apresentou nos últimos anos com grande redução de investimentos e retração de projetos, a necessidade de difusão de novas técnicas e métodos organizacionais que resultem em melhorias na eficiência e eficácia dos processos torna-se cada vez mais fundamental. 
De acordo com Ana Maria Castelo, coordenadora de Projetos da Construção da FGV IBRE, apesar dos indícios de retomada, as atividades do setor se encontram aquém de sua média histórica. Isso demonstra que, apesar das reduções atuais, a oportunidade de aquecimento do setor irá fomentar, e consequentemente haverá um aquecimento dos comércios distribuidores de materiais de construção. (NAKAMURA, 2019)

Uma projeção do Sindicato da Indústria da Construção do Estado de São Paulo (SindusconSP) em parceria com a Fundação Getúlio Vargas (FGV) demonstra que o Produto Interno Bruto (PIB) da construção civil brasileira deve crescer 2,0\% em 2019. Se confirmada essa estimativa, as constantes quedas nos níveis de atividades no setor, quantificada por um encolhimento $28 \%$ entre os anos de 2014 e 2018 no PIB, irá ter fim. (NAKAMURA, 2019)

Utilizando como base essas expectativas do setor, a opção por uma empresa de material de construção civil sem padrões de gestão definidos foi escolhida como objeto de estudo para a aplicação de mapeamento do processos capaz de auxiliar e gerar melhorias na prática. Importante ressaltar que a visualização dos problemas operacionais se dá por meio do fluxo de processos, que ao compreender as etapas sequenciais da empresa, permite a visualização dos gargalos de produção.

A sistematização das atividades em organizações administrativas é capaz de direcionar as ações e as rotinas diárias, gerando resultados definidos a fim de facilitar à organização e agregar valores à instituição. Assim, os resultados mais significativos para a gestão da empresa de material de construção civil escolhida para o estudo, no que diz respeito a seus produtos e serviços está ligado a eliminação de falhas, estruturação de processos, redução de custos e elaborando plano de ações para aplicação de melhorias em todas as atividades. Como destacado por Cunha (2012, p. 12), o mapeamento de processo "é uma atividade com o objetivo de desenhar, executar, documentar, monitorar e controlar a melhoria dos processos com vistas a alcançar resultados pretendidos numa organização institucional".

Segundo Ortega (2019) a industrialização atual afetará e transformará não somente na forma de viver, como também nas relações com o trabalho e humanas. Nota-se com isso, não apenas uma fase de desenvolvimento tecnológico, mas uma era de mudança de paradigma, comportamento e, principalmente, de transformação.

A partir desse conceito, é notório que a transformação digital no âmbito organizacional é um processo que consiste no uso da tecnologia para a melhoria de desempenho em diversos sentidos. Assim, empresas não tenham se modernizado correm o risco de serem ultrapassadas por seus concorrentes. Por isso, a adaptação do plano de negócio com processos definidos e 
controlados é fundamental para atender às demandas da Era da Informação. Assim, uma análise da estratégia da empresa pode ser considerada a primeira etapa para a permanência da mesma no mercado.

Tomando como partida um comércio de material de construção civil localizado em Niterói Rio de Janeiro, observa-se o desconhecimento de questões relacionadas a gestão do negócio. Dentre muitos, a falta de uma rotina ou manual de trabalho para realização de suas atividades pode consequentemente inviabilizar a padronização e melhor entendimento dos diferentes processos e procedimentos da empresa, por parte de seus colaboradores.

De acordo com (OSCAR, 2012), o ano de 2012 se caracterizou pelo boom do mercado da construção civil e, nesse cenário, a empresa atingiu seus melhores resultados. Contudo, assim como em todos os demais segmentos, a retração da economia nacional estagnou o mercado da construção civil a partir de 2014 (AMORIM, 2015), que por consequência, passou a recuar ano após anos seus níveis de demanda.

De acordo com o IBGE (Instituto Brasileiro de Geografia e Estatística), 2018 fechou com índices um pouco melhores quando comparados a 2017, porém negativos no período. Desde 2014, o setor possui uma retração de 27,7\%. (SOARES, 2019).

Dessa forma, a utilização do mapeamento de processos é capaz de trazer significativos resultados para a gestão de uma empresa no que tange seus produtos e serviços, visando a eliminando falhas, correção de deficiências, redução de custos e elaboração de um plano de ações aplicável nas melhorias das atividades.

Portanto, destaca-se a possibilidade de identificação de falhas capazes de serem trabalhadas com uso de ferramentas de gestão capazes de gerar resultados positivos para as empresas perante o concorrido mercado da construção civil.

\section{DESENVOLVIMENTO}

\subsection{Aspectos gerais da gestão de processos}

É sabido que o mundo passa por grandes e irreversíveis transformações. A globalização, rápidas mudanças tecnológicas, surgimento de novos padrões e necessidades sociais vem alterando como um todo as organizações atuais. Segundo Ferreira (2014), o surgimento de novas dinâmicas e modelos organizacionais está fortemente relacionada a esses fenômenos. Tanto no aspecto da eficiência, como a busca por ganhos de escala (ampliação do mercado em todo o mundo), somadas a grande e complexa cadeia de logística relacionada, têm estreita relação com a 
criação de megaconglomerados, uma vez que fusões, aquisições e alianças passam a ser fundamentais para a sobrevivência das empresas no mercado.

O cenário atual confirma a busca por adaptação ao ambiente externo e, principalmente, adaptação interna (da própria organização). A fim de se manter presente e conquistar uma parcela maior do mercado, as empresas procuram investir no entendimento e aprimoramento de seus processos. Isso porque, com a rapidez no surgimento de novas tecnologias, práticas e procedimentos precisam ser constantemente revisados a fim de não se tornarem obsoletos.

No que tange as empresas pode-se destacar a administração flexível. Está relacionada com a necessidade das empresas em identificar mudanças no cenário externo, sejam elas novas tecnologias, novas demandas dos clientes, mudanças no mercado, e agir de forma eficaz para gerar uma resposta capaz de suprir as novas condições. Tal sensibilidade é atingida quando as organizações entendem que as tradicionais estruturas organizacionais não se comportam mais com o sistema de gestão flexível atual. Assim, um sistema fechado, hierárquico, com comportamentos fortemente definidos e controlados passa a abrir caminho para estruturas dinâmicas e arbitrárias, suscetíveis a mudanças de acordo com as condições internas e externas. (FERREIRA, 2014)

Dessa forma, observa-se que a gestão de processos é um assunto no qual, dependendo das diversas condições e necessidades de demanda/mercado, novas práticas são desenvolvidas e aprimoradas. Grandes estudiosos da Engenharia de Produção desenvolveram metodologias que em sua aplicabilidade, mostravam um melhor desempenho operacional e, no decorrer dos anos, se tornaram incondizentes com as melhores práticas, o que gerava a oportunidade de se incorporar novas características na gestão do processo.

\subsubsection{Noções Gerais Da Gestão De Processos}

O ponto de partida para a compreensão das noções gerais da gestão de processos deve se dar pelo entendimento do significado de um processo. De acordo com Ferreira (2014) é possível observar que diversas definições identificam a presença de um sequenciamento lógico de atividades e tarefas, que estão sendo realizados com o intuito de se atingir um determinado resultado e/ou agregar valor a determinado insumo.

Em outras palavras, pode-se resumir processos pelo ordenamento de atividades no qual o objetivo final é a agregação de valor a determinado insumo (input) que gerará produtos ou serviços (outputs) que atendam a necessidade do cliente final. 
Importante destacar que a gestão de processos está diretamente relacionada a outros conceitos fundamentais da literatura. Abaixo serão tratados exemplos práticos/humanos, estratégicos e gerenciais constantemente utilizados na atualidade e que se relacionam com o controle e gestão dos processos de uma empresa.

Primeiramente pode-se destacar a estrutura organizacional como ponto de partida para uma empresa organizada e com foco nos resultados. Outro aspecto destacável é a cultura organizacional, que através de sua comunicação, motivação, reconhecimento, benefícios é capaz de extrair o melhor de seus colaboradores. Por fim, a maneira mais adequada de se mensurar essa produtividade é dada através dos indicadores de desempenho. Esses buscam gerar parâmetros para orientar e modificar cultura e comportamentos antes tidos como razoáveis pelas organizações. A figura 1 mostra a relação entre processos e metas de desempenho. (PAIM et al., 2009)

Figura 1 - Dimensões de um sistema de mediação

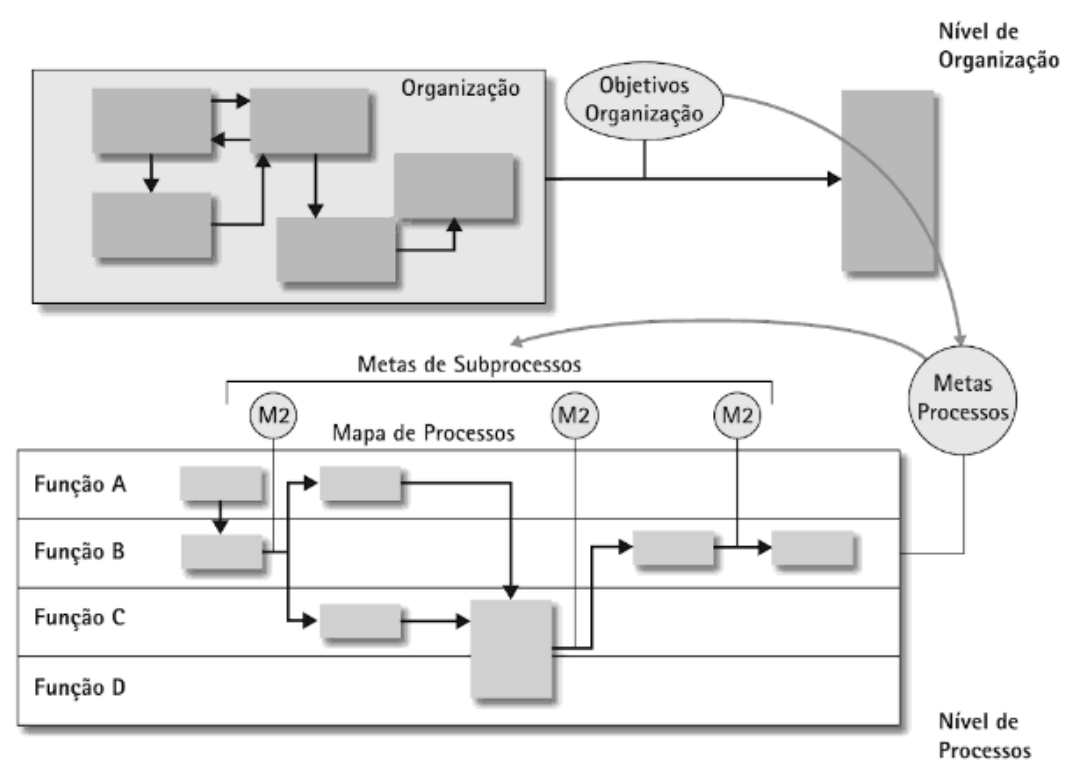

Fonte: PAIM et al. (2009)

Outra característica de uma empresa com seus processos estruturados está relacionada com sua estratégia empresarial. Isso porque existe uma metodologia capaz de relacionar os indicadores gerais da organização (sejam eles financeiros, de inovações, de mercado) com os específicos dos processos. A ferramenta mais difundida na atualidade denomina-se por Balanced Scorecard. (PAIM et al., 2009)

Em outras palavras, não basta apenas ter conhecimento dos processos e seus indicadores, sem os relacionar com a visão macro das estratégias da empresa. Assim, o Balanced Scorecard é a metodologia desenvolvida e reconhecida pela literatura para explicitar e demonstrar as estratégias operacionais da empresa. Por meio do scorecard, a empresa relaciona suas estratégias 
por meio de relações de causa e efeito de seus processos internos e ambiente externo, onde outros aspectos como o grau de correlação e estimativa dos tempos também compõem o quadro. (KAPLAN; NORTON, 1997)

Pode-se também citar um exemplo que se conecta com a gestão dos resultados encontrados no Balanced Scorecard. Também conhecido por Sistema Integrado de Gestão (SIG), este organiza o fluxo de informações que ocorrem em diversas áreas da empresa. Com o objetivo de tornar a gestão da organização realmente viável, realiza-se o ERP (Enterprise Resource Planning) e, com isso, relaciona a parte operacional da empresa por meio de sua cadeia logística de suprimento com P\&D, setores financeiros, comercial, assim como seus fornecedores e clientes. A figura 2 ilustra a relação de integração de processos com o ERP de uma organização. (PAIM et al., 2009)

Figura 2 - Interação de processos no ERP

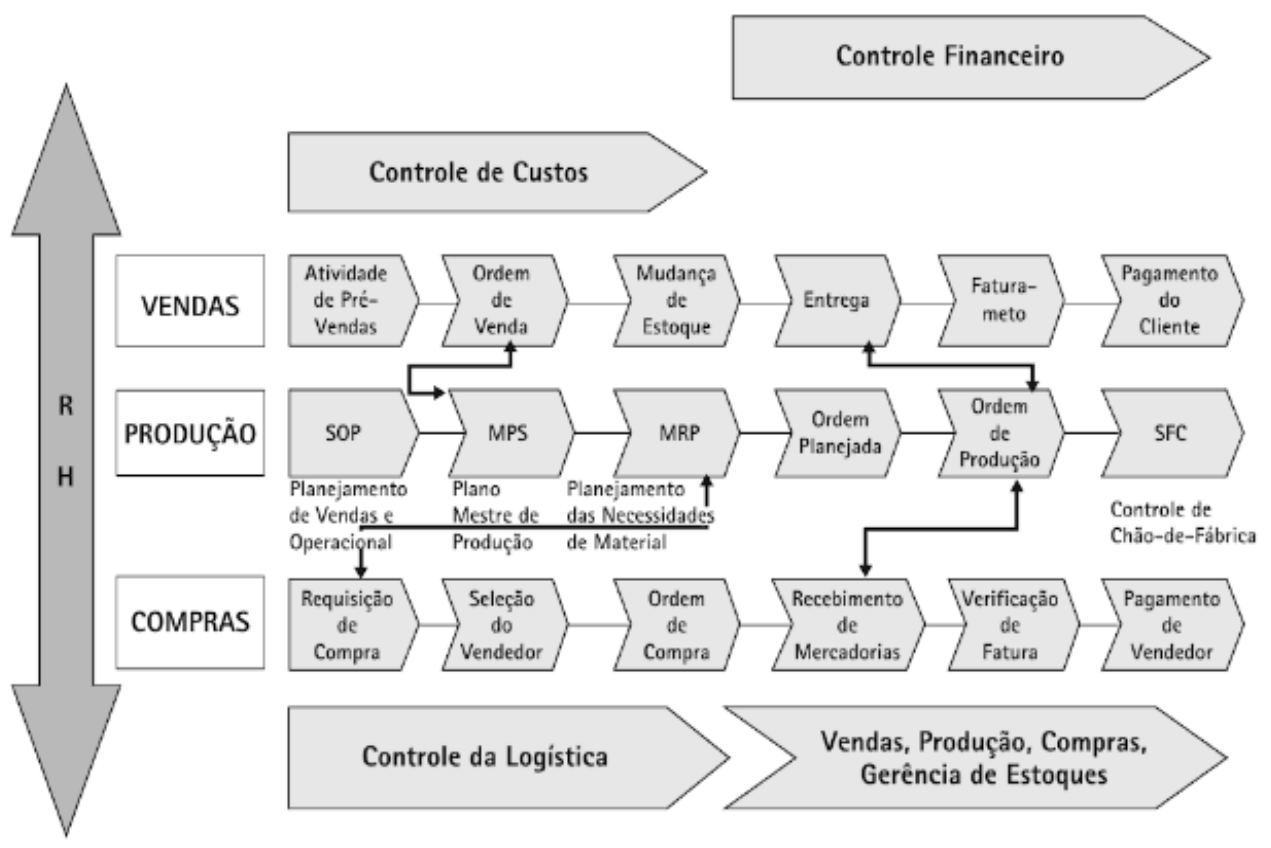

Fonte: PAIM et al. (2009)

É notório que os exemplos acima não se tratam de práticas iniciais para o controle dos processos. Todos partem do princípio de que os fluxos operacionais são previamente conhecidos e identificados. Estes, são obtidos por meio do mapeamento de processos. Ponto inicial de partida para qualquer projeto com objetivo de gerenciar os processos organizacionais, o BPMN será tratado no próximo tópico. 


\subsubsection{Aspectos Do Mapeamento De Processo BPMN}

Visando o entendimento do mapeamento de processo BPMN, é necessário inicialmente compreender a origem dessa notação. Com o decorrer dos anos, a busca constante por melhoria na qualidade dos produtos e serviços, redução dos custos de produção e crescimento nos lucros, as estratégias e decisões empresariais precisaram se desenvolver.

Nesse sentido, não somente a compreensão das práticas internas, mas também a valorização das necessidades dos clientes, abriram caminho para o início da administração das organizações por processos definidos de negócios. E, nesse âmbito, o mapeamento de negócios de popularizou por meio do Business Process Management (BPM).

Na década de 90, é possível destacar o Business Process Improvement (BPI). Segundo Capote (2012), o BPI, que na tradução literal para o português significa Melhoria de Processos de Negócio, utiliza da ideologia As Is para a identificação do chamado To Be. Em outras palavras, por meio da análise dos processos atuais da organização se viabiliza o desenvolvimento de propostas de melhorias dos processos, reformulando-os.

A notação BPMN se caracterizou como forma de representação do mapeamento de processos. Segundo Bruna Amaral, tal importância deriva da participação colaborativa de diversos países por meio do Object Management Group no desenvolvimento da notação. Vale destacar que o BPMI (Business Process Management Initiative) é associado ao OMG. (AMARAL, 2019)

Ainda nesse contexto, com a vantagem da padronização, e, portanto, compreensão de profissionais de diversas áreas na organização, o BPMN é caracterizado e desenvolvido por ícones, que auxiliam na implementação do BPM. (AMARAL, 2019)

O Diagrama de Processos de Negócio (DPN) organiza os diversos elementos que compõem um BPMN. Utilizando raias, uma organização estrutura suas atividades e processos identificados cronologicamente, por meio dos pré-requisitos necessários a cada. Nota-se também, a presença de objetos de fluxo, objetos de conexão, swim lanes e artefatos. (TOLFO; MEDEIROS; MOMBACH, 2013)

Pode-se traduzir de forma mais explicativa e prática os símbolos do BPMN. Assim, os conectores se identificam por setas que simbolizam o fluxo de atividades e mensagens. As atividades contemplam as mais diversas tarefas do mapeamento, dentre elas: tarefas simples, de serviço, de envio/recebimento de mensagens, de usuários, entre outros. Nos eventos se destacam três diferentes períodos do processo. No início, ícones de condicionais de tempo, mensagem, se destacam; no nível intermediário, temporizador, links, sinais, condicionais, mensagens; e no fim, 
encerramento, erro, compensação, mensagem, escalação, etc. Não menos importante, os gateways incluem fluxos exclusivos, paralelos, inclusivos, entre outros. A figura 3 ilustra os símbolos comentados acima.

Figura 3 - Notação BPMN 2.0

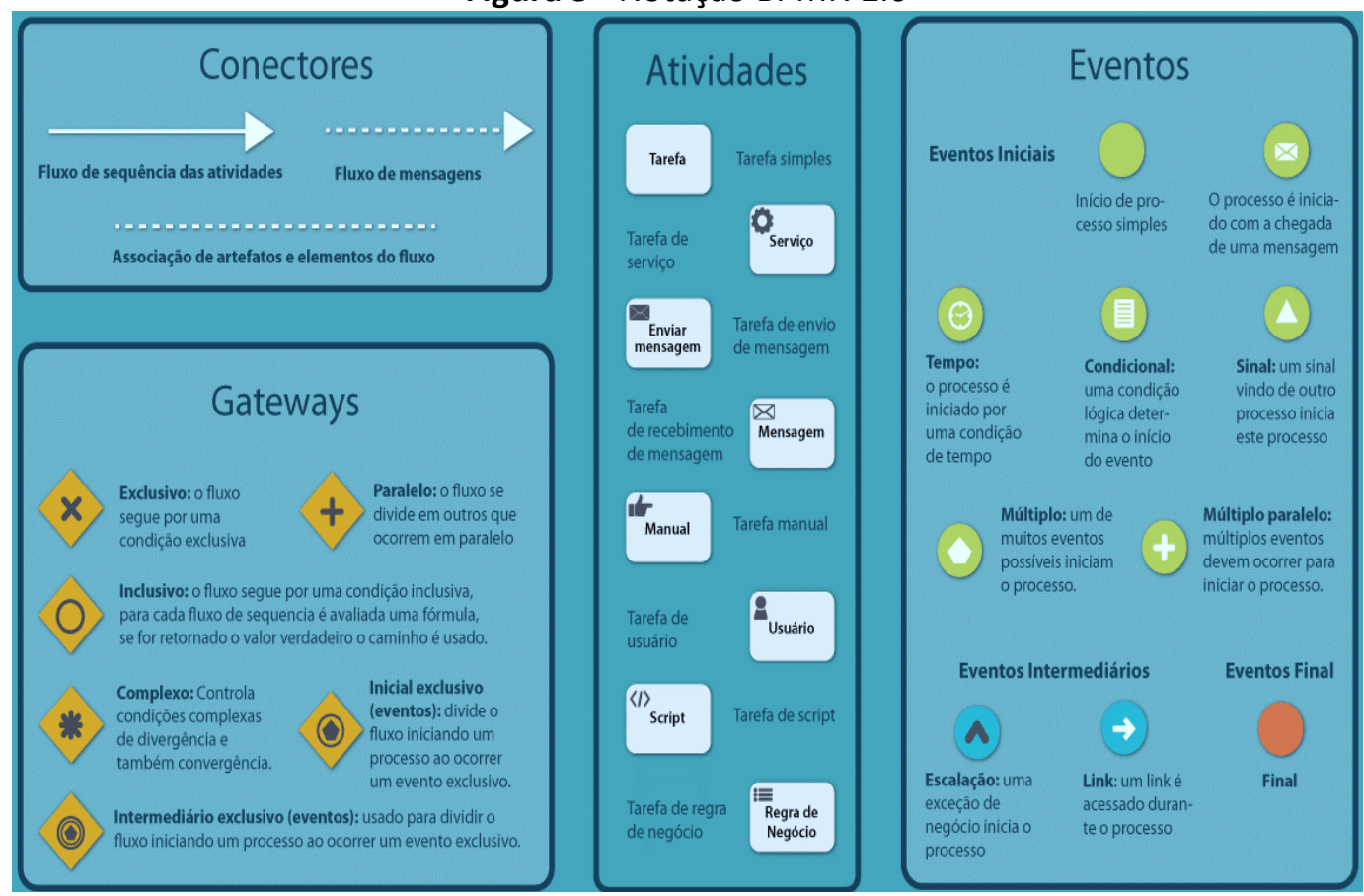

Fonte: Adaptado de Oliveira (2018)

Por fim, após compreendido o funcionamento da notação, destacam-se alguns dos diversos softwares e ferramentas de modelagem de processos. A mais famosa, o Bizagi Modeler foi desenvolvido pela Microsoft e está disponível de forma gratuita ao público. O site Heflo também contempla uma ferramenta gratuita, com uma interface leve, autoexplicativa e de fácil utilização. O Aris Express é uma versão light da Aris Plataform, uma plataforma de análise de processos conhecida. (OLIVEIRA, 2018)

\subsubsection{Aplicações Do Mapeamento De Processo Na Construção Civil}

Por se tratar de um mercado extremamente técnico e, em muitos casos, pouco gerenciável, o mapeamento de processo na construção civil adquire uma relevância destacável. Considerando a ampla abrangência do setor, pode-se identificar desde obras de pequenos reparos residenciais a grandes construções públicas; pequenos comércios de distribuição a grandes redes varejistas de venda de materiais; trabalhadores autônomos ao mundo corporativo das empreiteiras. 
Outro aspecto considerável sobre a construção civil denomina-se pela incerteza. Estreitamente relacionado com o inadequado gerenciamento dos processos, em muitos casos, observa-se construções com alto custo, com a qualidade do produto final incerta, assim como seu tempo estimado de finalização. Além disso, a desqualificação da mão de obra necessária representa grande influência na baixa produtividade dos trabalhadores. (SILVA; LAPOLLI, 2001)

Por tal característica, o mapeamento de processos é capaz de identificar, controlar e entender diversos aspectos que antes fluíam de acordo com o momento. Como já comentado, todo processo é único, logo o conhecimento adquirido e o estudo constante sobre os métodos aplicados deve ser sempre atualizado. Ainda de acordo com Silva e Lapolli (2001), é crucial a identificação considerando o descarregamento do material, como ponto inicial, até a entrega do processo. O detalhamento dos dados das atividades e subprocessos relacionados a parte do "desenvolvimento", também precisam estar documentados.

Analisando alguns casos no meio da construção, pode-se destacar a funcionalidade da aplicação do mapeamento de processos em:

- Obras: auxiliando na definição do fluxo de execução das atividades, quem é responsável por cada etapa, indicadores de desempenho, controle dos tempos

- Distribuidores: ajudando na identificação da operação, gestão da mão de obra, controle de estoque, análise da demanda, entendimento dos prazos financeiros

O estudo do Morais Júnior (2014), destaca que o mapeamento de processos é capaz de gerar inúmeras melhorias ao segmento da construção. As contribuições no caso foram relacionadas ao alinhamento estratégico, $\mathrm{TI}$, desempenho, especialização e contribuição dos colaboradores, padronização e propostas de melhorias dos processos, entre outros.

Em contrapartida, as limitações se destacam pelo fato de que algumas propostas de melhorias podem levar meses para serem aplicadas, dificultando a comparação entre o antes e depois no desempenho dos processos. Além disso, subprocessos relacionados com a medição dos serviços (indicadores de controle) podem acabar sendo menos explorados que o possível, dependendo do escopo e tempos definidos à pesquisa. (MORAIS JÚNIOR, 2014)

Segundo Araújo (2018) foi aplicado mapeamento em uma empresa de construção civil, as vantagens da aplicação dessa filosofia foram diversas: maior conhecimento da empresa, envolvimento de toda a equipe, surgimento de ideias de melhoria, redução dos custos, minimização das falhas, entre outros. Além disso, foi possível notar que uma gestão por processos respaldada pela aplicação de sistemas que auxiliassem na nova execução dos processos seria o caminho para se alcançar constantemente melhores resultados. 0 quadro 1 ilustra os 
participantes e o status do resultado após o mapeamento dos processos em uma empresa de construção civil.

Quadro 1 - Processos da empresa após o mapeamento

\begin{tabular}{|l|l|l|}
\hline \multicolumn{1}{|c|}{ Processo } & \multicolumn{1}{|c|}{ Colaboradores } & \multicolumn{1}{c|}{ Status } \\
\hline Arquivamento de Contas & Auxiliar Administrativo & Novo \\
\hline Arquivamento de Documentos & Auxiliar Administrativo & Novo \\
\hline Cadastro Cliente Novo & Auxiliar Administrativo & Novo \\
\hline Cadastro de Fornecedores & $\begin{array}{l}\text { Auxiliar Administrativo } \\
\text { e Administradora }\end{array}$ & Redesenho \\
\hline Emissão de Nota Fiscal & Auxiliar Administrativo & Redesenho \\
\hline Emissão Pedidos e Orçamentos & Auxiliar Administrativo & Redesenho \\
\hline Entrega (Logística) & Logística & Redesenho \\
\hline Notas Fiscais Contador & Auxiliar Administrativo & Redesenho \\
\hline Pedido Ducasse & Auxiliar Administrativo & Redesenho \\
\hline Pedido Killing & Auxiliar Administrativo & Redesenho \\
\hline Pedido Maná & Auxiliar Administrativo & Redesenho \\
\hline Resumo de Embarque & Auxiliar Administrativo & Redesenho \\
\hline Tabela de Preços Cliente & $\begin{array}{l}\text { Auxiliar Administrativo } \\
\text { e Administradora }\end{array}$ & Novo \\
\hline
\end{tabular}

Autor: (Adaptado de Araújo, 2018)

Nota-se, portanto, que o vasto e variável campo da construção civil carece de práticas de gestão capazes de auxiliar numa melhor produtividade e controle das atividades. Dessa forma, não somente o que tange a operação, mas toda a parte financeira, previsão de tempo, divulgação, solução de problemas são contempladas e melhoradas após um mapeamento de processo das atividades em questão.

\section{METODOLOGIA}

O estudo foi realizado em um comércio familiar, pequeno, no qual a economia influenciou fortemente no seu desempenho em vendas. Após entendido esse cenário, partiu-se para o entendimento da empresa em si. Suas necessidades puderam ser enxergadas por meio de reuniões entre sócios, conversas com a equipe e análise da base de dados histórica de vendas realizadas pela mesma. Os temas a serem discutidos e propostos estavam esclarecidos, onde de forma resumida: por meio do mapeamento de processos seriam identificadas variáveis críticas na operação que, após seu entendimento, seria executado o novo mapeamento de processos para solucioná-los. 


\section{ANÁLISE DOS RESULTADOS}

\subsection{Apresentação do projeto/problema}

A empresa de vendas de material de construção estudada localiza-se em Itaipu - Niterói, no estado do Rio de Janeiro. A localização de destaque para a região viabiliza um fácil acesso tanto para os clientes, quanto para os fornecedores. Esta empresa foi originada em 2005 e nesse início, foi composta por 4 funcionários, com crescimento em vendas identificado com o decorrer dos anos e atingindo um número máximo de 15 funcionários. Sua organização atual compõe 2 sócios proprietários, 2 vendedores, 1 motorista trabalhando de forma individual voltado para a busca de materiais para o fornecimento interno do estoque e dois motoristas voltados para a entrega de material para o consumidor final, onde cada motorista é auxiliado por 2 assistentes (o número de motoristas para entrega + assistentes varia de acordo com a demanda). A figura 4 abaixo ilustra o organograma atual.

Figura 4 - Organograma da Empresa

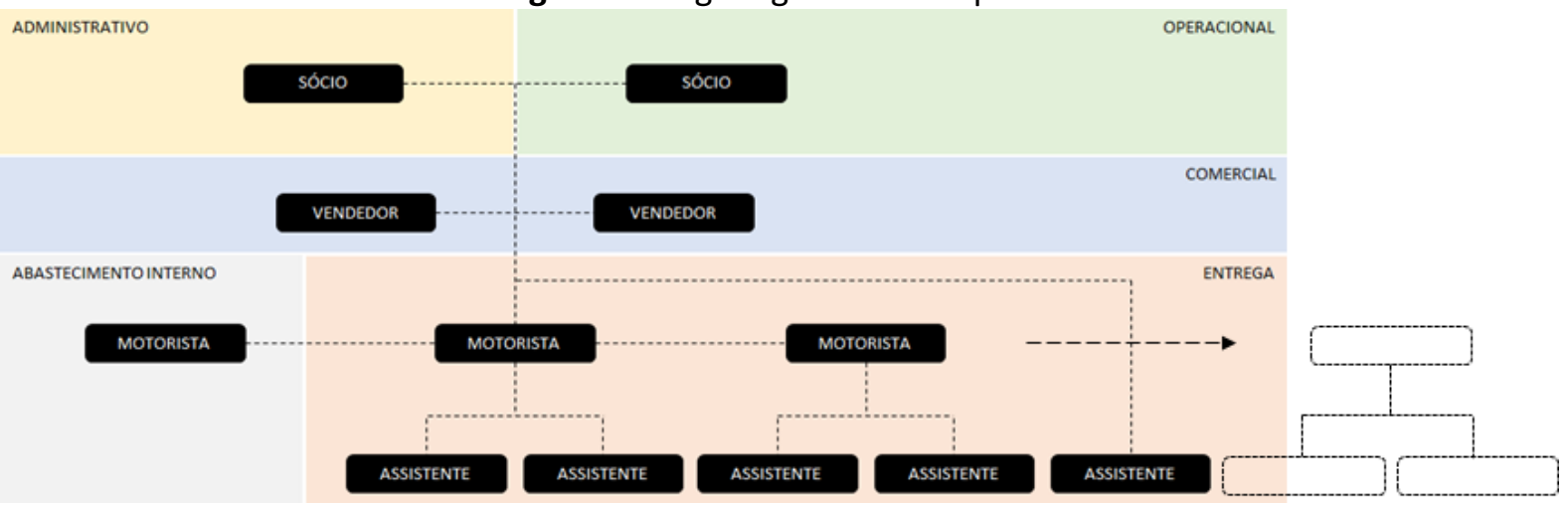

Fonte: Elaborado pela autora

Como observa-se a redução de vendas na figura 13 , se tornou necessário não somente uma diminuição do quadro de funcionários, como também o completo entendimento da operação e do funcionamento da empresa, visando conter os custos e manter-se rentável.

Identifica-se na loja de Material de Construção um comércio varejista distribuidor de materiais brutos para a construção. Dentre os principais produtos comercializados, destacam-se: tijolo cerâmico, bloco de concreto, cimento CPIII e CPII, areia, areola, brita, escora, sarrafo, entre muitos outros que contabilizam mais de 1.000 opções diferentes já disponíveis ao consumidor final. O quadro 2 ilustra em ordem decrescente os produtos com maior número de vendas identificados na empresa entre os anos de 2016 a 2019. 
Quadro 2 - Produtos da Empresa em análise

\begin{tabular}{|c|}
\hline Produto \\
\hline Tijolo cerâmico unid. $20 \times 30$ \\
\hline Tijolo cerâmico unid. $20 \times 20$ \\
\hline Saco de areia \\
\hline Cimento CSN CPIII \\
\hline Bloco concreto $15 \times 20 \times 40$ \\
\hline Bloco concreto $10 \times 20 \times 40$ \\
\hline Tabua 30 cm c/ $3 \mathrm{~m}$. \\
\hline Saco de brita \\
\hline Saco areia fina \\
\hline Cimento holcim CP III \\
\hline Cal hidratado votoran \\
\hline Saco de areola \\
\hline Escora eucalipto 3 m. \\
\hline Cimento tupi CPII \\
\hline Areia $\mathrm{m}^{\mathbf{3}}$ \\
\hline Sarrafo $15 \mathrm{~cm}$ c/ $3 \mathrm{~m}$. \\
\hline Clarofilito $20 \mathrm{Kg}$ \\
\hline Sarrafo $10 \mathrm{~cm}$ c/ $3 \mathrm{~m}$. \\
\hline Parafuso telha \\
\hline
\end{tabular}

Fonte: Elaborado pela autora

Importante destacar dentre as principais características de um comercio revendedor de material de construção que a preocupação com quesitos como validade e durabilidade dos produtos pode ser em sua maioria desconsiderados, uma vez que os prazos são muito maiores quando comparados ao tempo que o produto fica em estoque. Por outro lado, produtos advindos de origem natural, como por exemplo areia e areola, podem ter sua qualidade alterada dependendo do local de retirada dos mesmos.

Em relação as condições internas, é fundamental a disponibilidade de equipamentos como caminhão, escavadeira, entre outros, para que a operação da empresa possa ser realizada. No aspecto externo, as condições climáticas influenciam de forma destacável o prosseguimento das obras ou uma paralisação momentânea, uma vez que chuvas inviabilizam a execução de diversas etapas na construção. Destaca-se também a identificação do tipo de obra para saber quais materiais que se adequam, assim: reforma ou construção do zero, casa ou apartamento. Também com importância, existe o período em que a obra se encontra: estrutura, alvenaria, cerâmica, telhado, pintura, embosso, parte elétrica e hidráulica, acabamento, entre outros.

As principais características do comércio em questão, os problemas notados pelos colaboradores podem ser classificados em um grande tema: falta da aplicação de práticas de 
gestão. Ou seja, o entendimento da parte técnica, operacional e logística referentes ao negócio possuem um excelente desempenho quando comparado aos conhecimentos de gestão aplicados visando um melhor desempenho da empresa. Ao analisar os pontos mais específicos, foi possível identificar a causa destes problemas, que serão expostos abaixo:

a) Gestão improdutiva da disponibilidade dos produtos

A maior influência neste quesito está ligada ao não conhecimento e noção sobre o futuro da empresa. Em outras palavras, a previsão da demanda auxilia no entendimento das necessidades de oferta dos produtos da empresa, o que interfere de forma direta com o abastecimento da mesma. Isso porque ao esperar determinado desempenho de vendas nos meses seguintes, a quantificação dos materiais disponíveis necessários pode ser realizada previamente.

b) Falta de produtividade operacional

Este tópico é causado pela inexistência de processos estabelecidos, sendo todos realizados de forma despadronizada e com seu solucionamento de problemas ocorrendo de forma reativa. Ou seja, a falta do entendimento dos processos realizados pela empresa inviabiliza um estudo sobre melhores práticas, gestão do tempo, redução de custos, entre outros. Vale lembrar que ao se tratar de uma microempresa, muitos de seus procedimentos são manuais e, com isso, poderiam ser melhor realizados.

c) Redução na demanda dos produtos

Por forte influência da crise no setor, as vendas realizadas pela empresa diminuíram de forma considerável. Ao mesmo tempo, o investimento em marketing visando a atração de novos clientes, expansão na parcela do mercado, elaboração de descontos e promoções não existe, ou seja, estratégias focadas na obtenção de novos clientes e a fidelização dos mesmos não são realizadas.

A escolha do tópico a ser estudado e analisado nesse trabalho destaca-se pela "Falta de Produtividade Operacional", no qual foi aplicado a ferramenta do mapeamento de processos. Isso se justifica uma vez que melhorias na produtividade da operação da empresa podem ser alcançadas com o conhecimento das etapas e processos da operação. 


\subsection{Análise de resultados atuais}

Considerando a análise dos dados de vendas relativos à soma das quantidades dos 20 produtos com maior demanda entre janeiro de 2016 e junho de 2019 conforme ilustra a figura 5, nota-se uma variação nos números totais de venda.

Figura 5 - Quantidade de vendas mensal

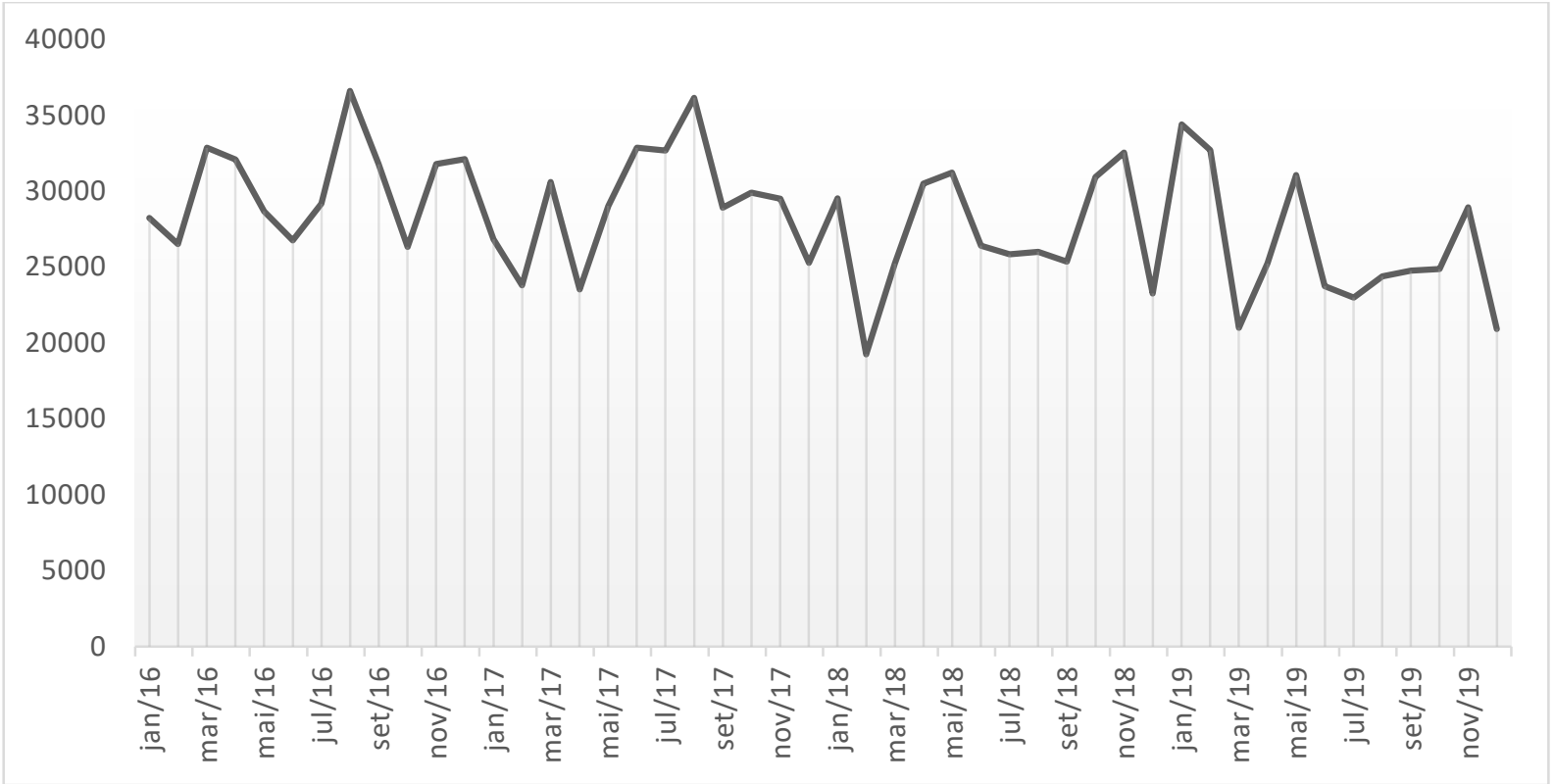

Fonte: Elaborado pela autora

Os resultados mensais da empresa, demonstram que de fato o cenário atual não manteve os mesmos índices de 2016. Como já citado, os cenários político e econômico influenciaram no desempenho da empresa, reduzindo de forma destacável sua atividade ao comparar os anos 2016/2017 com 2018/2019. Além disso, a comparação entre meses de anos diferentes não permite uma conclusão precisa sobre a sazonalidade das vendas, uma vez que nota-se a variação da demanda.

Considerando agora uma análise mais individual a respeito de cada caso, é importante citar que a quantidade mensal de vendas de cada item possui variabilidade nos números, uma vez que os materiais são classificados por diferentes unidades, como por exemplo: tijolos e blocos são vendidos por unidade, areia e aréola por $\mathrm{m} 3$, escora e sarrafo por $\mathrm{m} 2$, cimento por $\mathrm{kg}$, dentre outros.

\subsection{Mapeamento do processo atual}

Considerando o problema da "Falta de Produtividade Operacional" descrito no item, a ferramenta do Mapeamento de Processo BPMN foi aplicada na empresa visando identificar e 
compreender as diferentes etapas realizadas pela empresa, desde o pedido inicial do cliente à entrega final do material.

Inicialmente o cliente precisa ser direcionado ao estabelecimento e solicitar o material desejado aos vendedores do estabelecimento. A checagem sobre a loja vender ou não o produto é realizado de forma verbal, uma vez que os atendentes conhecem todos os produtos que a loja trabalha. Em caso negativo, o processo é encerrado sem a realização da venda. A figura 6 ilustra esse caso.

Figura 6 - Exemplo Processo Completo 1

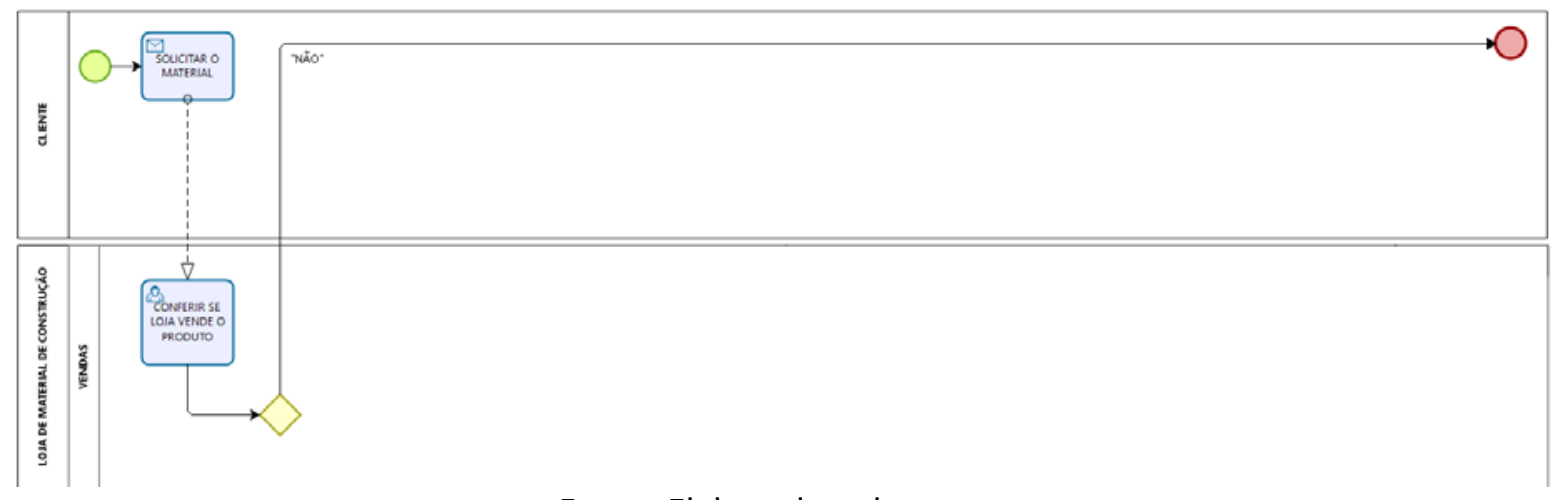

Fonte: Elaborado pela autora

Em caso positivo, o vendedor efetua a venda ao cliente e em seguida confere a disponibilidade do material em estoque. Havendo o produto disponível é verificada a disponibilidade da loja em entregar o produto. Com a data definida, é informada ao cliente que, estando de acordo, combina a forma de pagamento do material. Após isso, a compra é finalizada e o pagamento realizado. Caso a data de entrega não satisfaça o cliente, o processo é encerrado.

$\mathrm{Na}$ data da entrega do material, os motoristas e assistentes são informados sobre o planejamento, fazem o carregamento do caminhão com os itens e se direcionam ao local de descarregar, finalizando assim o processo.

Observa-se, contudo, o risco de inadimplência por parte dos clientes, uma vez que considerando que a entrega seja realizada antes do pagamento, o consumidor não possui motivo real para quitar sua dívida. Assim, outros débitos podem ser priorizados fazendo com que a loja fique sem o dinheiro e sem o material. A figura 7 ilustra essa etapa.

Considerando a inexistência do material em estoque, os vendedores checam se o material é entregue por fornecedores ou se a loja que vai ao fornecedor buscar o material. No primeiro caso, um pedido de entrega é solicitado e após o recebimento (em grande maioria $24 \mathrm{~h}$ ) o material é entregue ao cliente. No segundo, a loja se direciona ao local de coleta do material para reabastecer o estoque (em grande maioria $24 \mathrm{~h}$ ) e também realiza a entrega na data combinada. 
Nas duas situações, o processo se encerra com a venda efetuada, pagamento realizado, data de entrega acordada e o material entregue.

Figura 7 - Exemplo Processo Completo 2

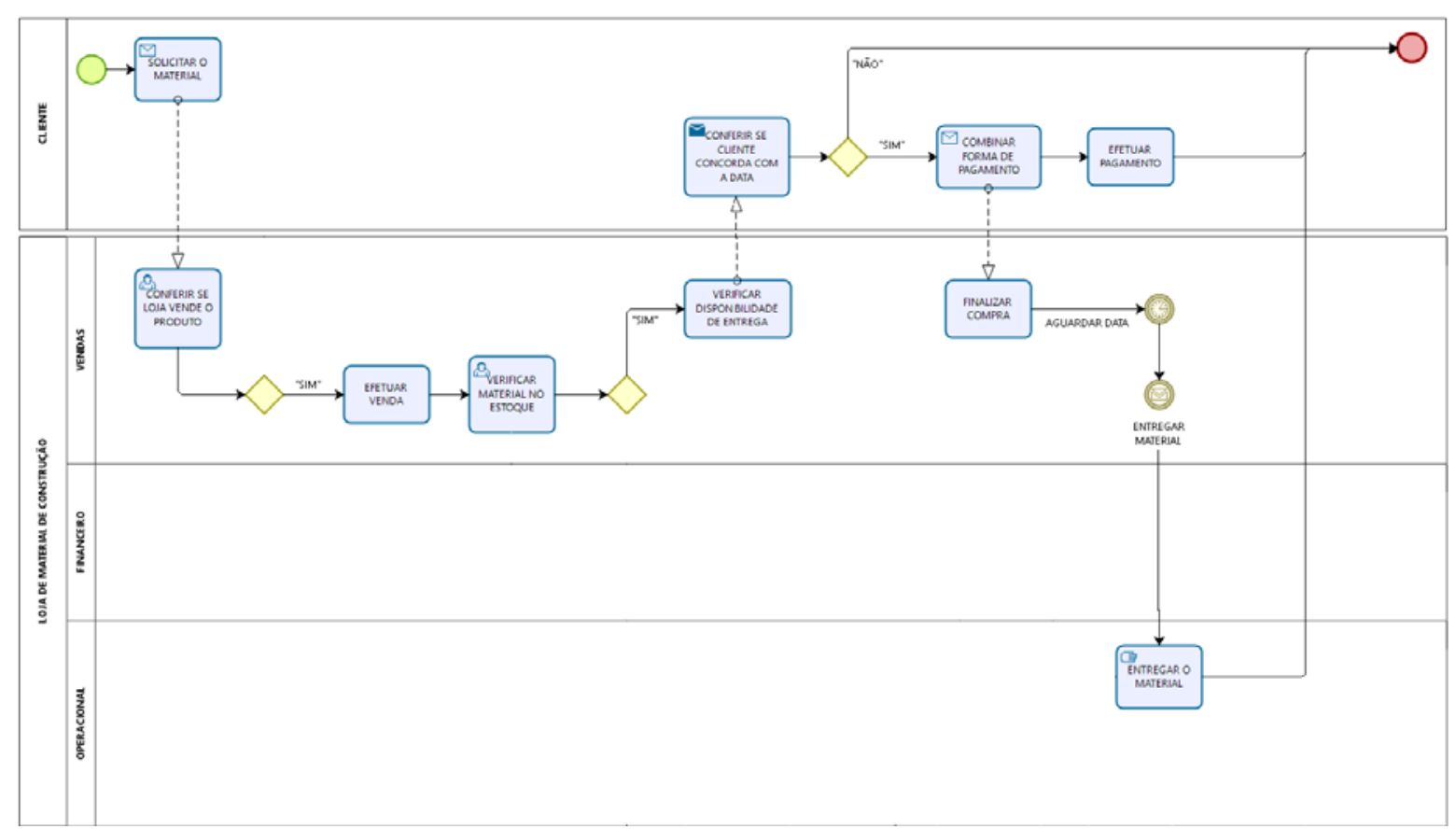

Fonte: Elaborado pela autora

Neste caso, um problema verificado é que em caso de cancelamento da compra, nota-se um acúmulo de produtos em estoque e a consequente redução do capital de giro. Em outras palavras, uma vez solicitada a demanda e a loja não tendo tal produto disponível, a mesma realizará a compra, que deverá ser em grande volume visto altos custos de frete e, considerando a urgência em não perder a venda, terá preços mais elevado. Caso o cliente não efetue o pagamento e desista da compra, esse material ficará acumulado em estoque, demandando espaço suficiente para armazenamento, e ao ser vendido gerará uma margem de lucro menor ao comércio.

O outro problema está relacionado com a incerteza da disponibilidade dos produtos (gestão improdutiva da disponibilidade dos produtos). Ou seja, considerando que a empresa tenha conhecimento sobre sua demanda e consiga prever suas vendas, jamais haveria falta de material em estoque. Isso evitaria o problema citado acima sobre pagar um preço mais elevado pela urgência em se ter determinado material. Assim como também é capaz de interferir na a perda de clientes fixos ou potenciais (que irão comprar o material indisponível na concorrência). A figura 8 ilustra essas observações. 
Figura 8 - Exemplo Processo Completo 3

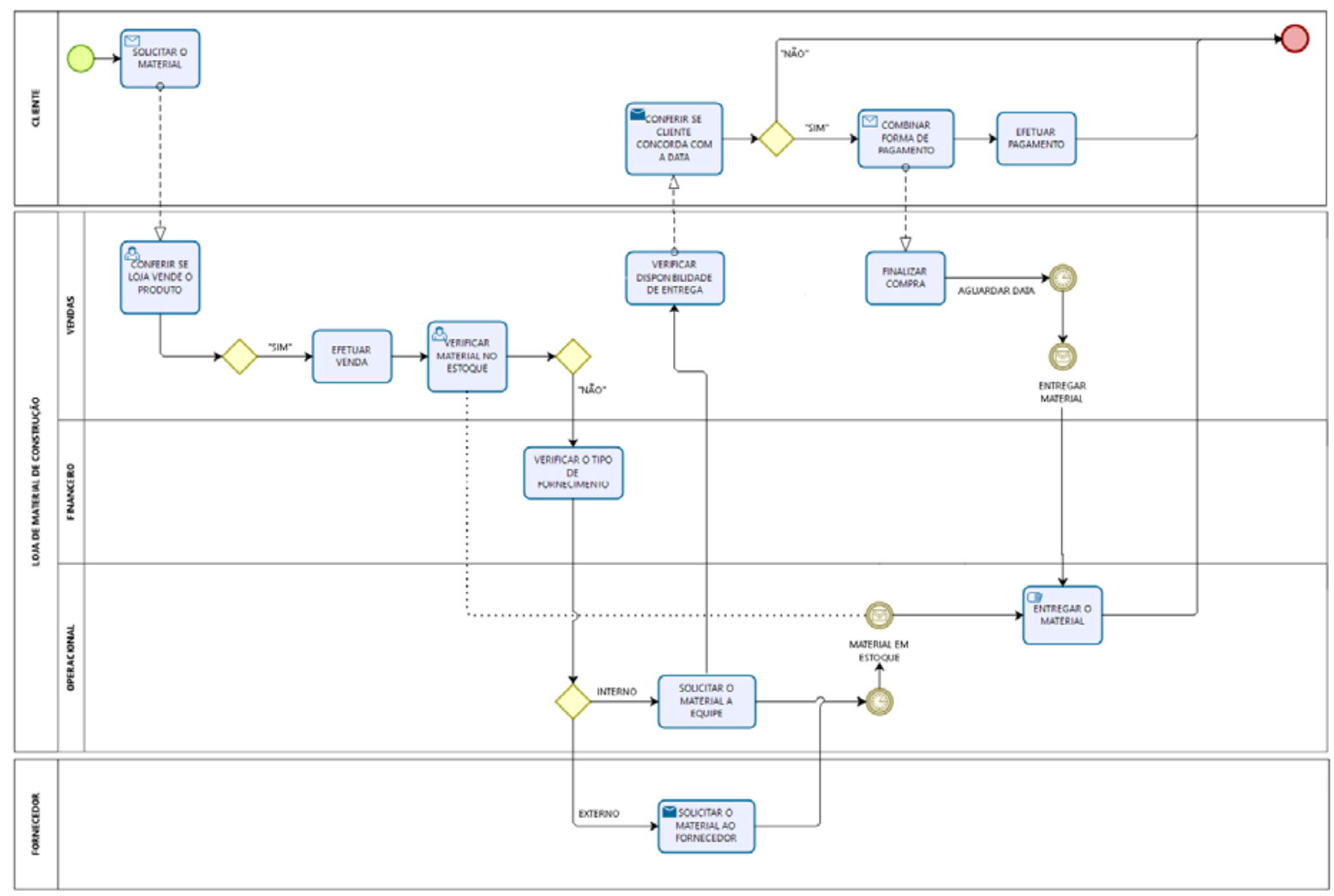

Fonte: Elaborado pela autora

Em paralelo a operação, o financeiro viabiliza os pedidos aos fornecedores e busca dos materiais, se comunicando com todas as etapas e efetuando os pagamentos e questões financeiras necessárias.

Destaca-se nessa etapa um gargalo de enorme influência na produtividade da empresa (falta de produtividade operacional). Carretas como por exemplo as de cimento, tábua e tijolo, precisam de algumas horas para serem descarregados manualmente. Por tal motivo, além de ocupar parte do estoque com o caminhão parado, dificultando a movimentação de veículos e pessoas no local, a mão de obra voltada para entregas (motoristas e assistentes) precisa interromper e/ou revezar tal ofício para auxiliar no descarregamento do material.

Por consequência, em caso de um grande número de entregas a serem realizadas no dia em questão, algumas precisarão ser postergadas para o dia seguinte. Com isso, existe a chance do cliente ficar insatisfeito com tal descumprimento de acordo, procurando outras empresas que sejam eficazes ao planejamento. A figura 9 ilustra essa etapa. 
Figura 9 - Exemplo Processo Completo 4

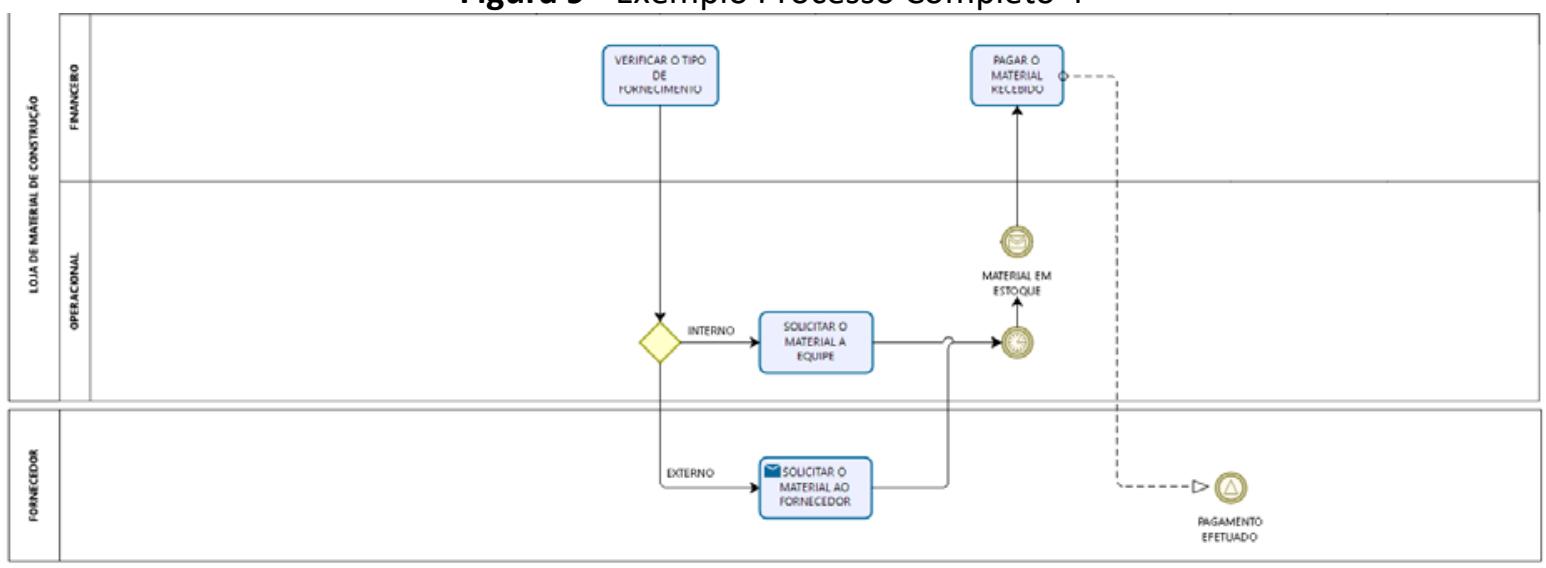

Fonte: Elaborado pela autora

\subsection{Sugestão do novo mapeamento do processo atual}

Tendo em vista a busca por melhorias na gestão dos processos da empresa em questão, os principais problemas notados no mapeamento de processos e discutidos no capítulo acima são:

1. Pagamento após a entrega do material influencia no aumento da inadimplência dos clientes;

2. Sem conhecimento da demanda é comum a incerteza se o produto pedido pelo cliente se encontra disponível em estoque;

3. Considerando o cliente pedir o material, a empresa não o ter no momento e solicitá-lo com urgência aos fornecedores e o cliente cancelar a compra, nota-se um acúmulo de produtos em estoque e a consequente redução do capital de giro;

4. Determinadas carretas com materiais são descarregadas manualmente, o que gera problema por: demorar várias horas para concluir o descargue, o caminhão ocupar boa parte do espaço físico da loja, necessitar da mão de obra voltada para entregas para auxiliar na retirada do material (inviabilizando realização de entrega simultaneamente).

Analisando todos os gargalos descritos, um novo mapeamento foi sugerido. Este visa solucionar os problemas de número 1 e 3 citados acima. Em suma, as práticas bem executadas foram mantidas, alterando algumas as etapas que geram aumento nos custos e redução de produtividade. A figura 10 demonstra o mapeamento de processos sugerido. 
Figura 10 - Novo Mapeamento de Processos

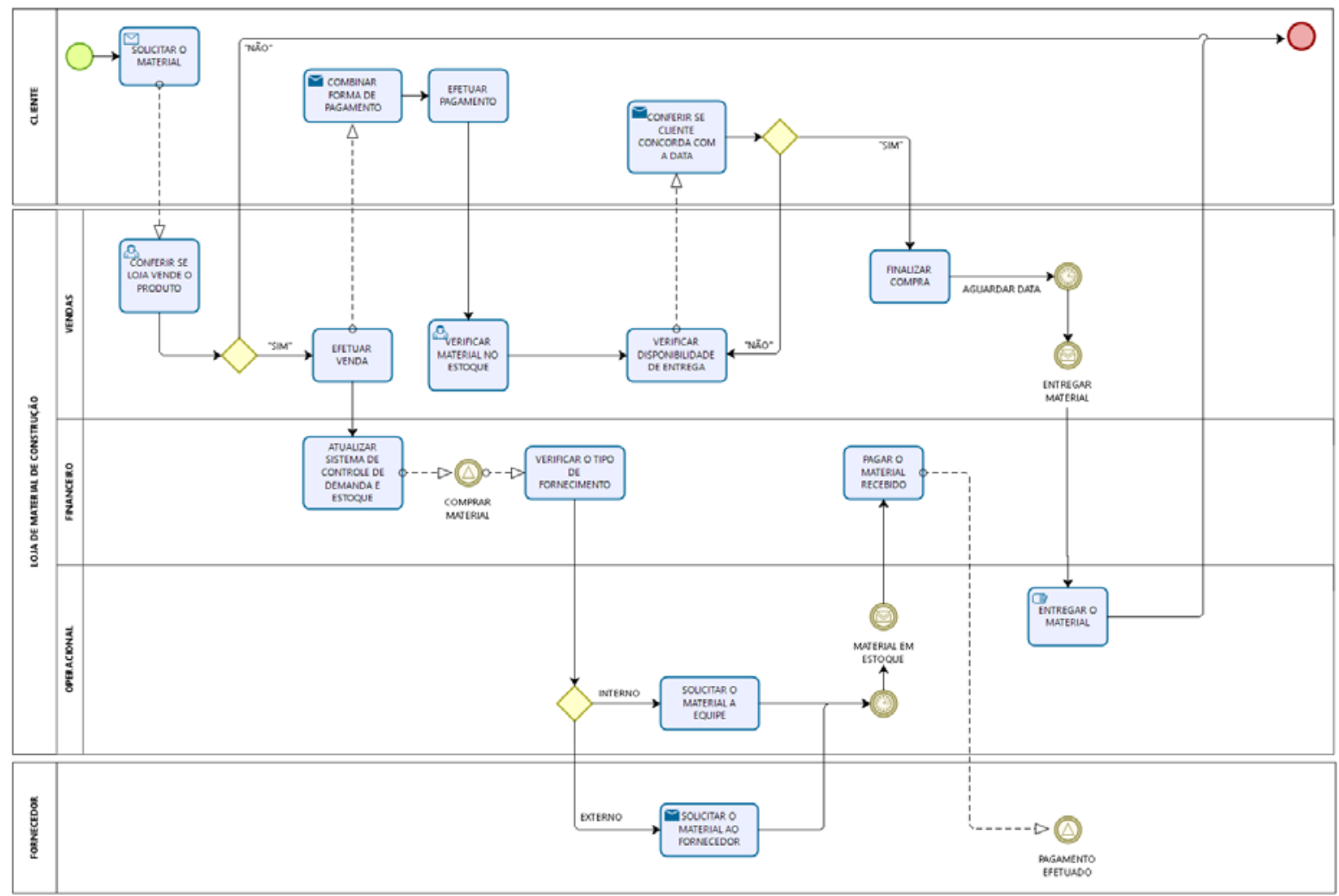

Fonte: Elaborado pela autora

A primeira observação de mudança no mapeamento acima está na antecipação da etapa de pagamento. Assim, ao invés da empresa correr o risco de não receber, o cliente se torna o responsável pela liberação da entrega, uma vez que essa será realizada apenas após a quitação de débito. Com tal ajuste, o que antes era identificado como uma ameaça no crescimento da inadimplência, agora passa a ser considerado como etapa inicial e de pré-requisito para o prosseguimento dos processos.

Outro ponto alterado que é fundamental para que a solução acima possa ser implementada, é a inserção da gestão de estoque e previsão a demanda futura. Com isso, reduziriam os riscos de determinado produto estar indisponível, como no mapeamento atual, o que soluciona dois problemas identificados: o risco de não ter o produto em estoque e a necessidade do acionamento de última hora dos fornecedores, que em caso da compra do cliente não ser finalizada, acumula na empresa materiais com custo mais elevado. Além disso, tal previsão também auxiliaria na diminuição de conflito entre descarregar um fornecimento e realizar as entregas rotineiras de material da loja.

Nota-se com o novo mapeamento a necessidade da previsão de demanda para ter conhecimento dos volumes de venda e a consequente influência de tal produto na operação da 
empresa. Com isso, as aquisições necessárias tem a possibilidade de serem realizadas no momento ideal, não necessitando investimento em um período cujo volume de vendas não justifica tal aporte. Além disso, enquanto a aquisição não for realizada, a previsão auxilia no conhecimento do volume futuro de vendas, mantendo as etapas do novo mapeamento em sinergia.

\section{CONSIDERAÇÕES FINAIS}

Sabendo das condições político econômicas no cenário atual no Brasil, o mercado da construção civil sofre forte impacto no desenvolvimento. Tendo em vista se manter estável frente às inúmeras mudanças, empresas precisam se adaptar para conquistar parcelas de mercado antes pertencentes aos concorrentes, reduzir custos e buscar aumentar sua margem de lucros.

Nota-se que o foco de trabalho esteve desde início em solucionar as causas focais da falta de produtividade operacional. Através dos 20 produtos de maior quantidade de venda, um mapeamento de processos foi realizado e reformulado visando diminuir os gargalos de produção.

\section{REFERÊNCIAS}

AMARAL, Bruna. Notação BPMN: o que é e quando usar? Disponível em: <https://blog.smlbrasil.com.br/o-que-significa-bpmn/>. Acesso em: 19 nov. 2019.

AMORIM, Lucas. Construção civil vive crise sem precedentes no Brasil. Revista Exame, 16 jul. 2015. Disponível em: <https://exame.abril.com.br/revista-exame/a-crise-e-a-crise-daconstrucao/>. Acesso em: 21 nov. 2019.

ARAÚJO, Thayse Layse Dias. Mapeamento de processos: estudo em uma empresa de material para construção civil. 2018. 51 f. Trabalho de Conclusão de Curso (Bacharelado) - Universidade Federal do Maranhão, São Luís, 2018. Disponível em: <https://monografias.ufma.br/jspui/bitstream/123456789/1958/1/Thayse\%20Layse\%20Dias\%20A ra\%c3\%bajo.pdf>. Acesso em: 19 nov. 2019.

CAPOTE, Gart. BPM para todos: uma visão geral abrangente, objetiva e esclarecedora sobre gerenciamento de processos de negócio. Rio de Janeiro, 2012.

CUNHA, Alex Uilamar do Nascimento. Mapeamento de processos organizacionais na UnB: caso Centro de Documentação da UnB - CEDOC. 2012. 66 f. Monografia (Especialização em Gestão Universitária) - Universidade de Brasília, Brasília, 2012. Disponível em: <http://www.bdm.unb.br/handle/10483/4191>. Acesso em: 19 nov. 2019. 
FERREIRA, André Ribeiro. Gestão de processos: módulo 3. Brasília: ENAP, 2014. Disponível em: $<$ https://repositorio.enap.gov.br/bitstream/1/2332/1/1.\%20Apostila\%20-

\%20M\%C3\%B3dulo\%203\%20-\%20Gest\%C3\%A30\%20de\%20Processos.pdf>. Acesso em: 19 nov. 2019.

JORNAL ESTADO DE MINAS. PIB da construção civil deve crescer 2\% em 2019, diz Sinduscon-SP. Disponível em: <https://www.em.com.br/app/noticia/economia/2019/02/05/internas_economia,1028015/pibda-construcao-civil-deve-crescer-2-em-2019-diz-sinduscon-sp.shtml>. Acesso em: 19 nov. 2019.

KAPLAN, Robert S.; NORTON, David P. A estratégia em ação: balanced scorecard. Rio de Janeiro: Elsevier, 1997.

MORAIS JUNIOR, Nivaldo Pereira de. Melhoria do processo de gestão da construção civil com uso da disciplina BPM. 2014. 169 f. Dissertação (Mestrado em Engenharia) - Pontifícia Universidade Católica Go Goiás, GOIÂNIA, 2014.2 Disponível em: <http://tede2.pucgoias.edu.br:8080/handle/tede/2455>. Acesso em: 22 nov. 2019.

NAKAMURA, Juliana. Tendências da construção civil. Disponível em: <https://www.buildin.com.br/tendencias-da-construcao-civil-2/>. Acesso em: 19 nov. 2019.

OLIVEIRA, Wallace. Notação BPMN, a mais usada para modelar processos. 2018. Disponível em: <https://www.heflo.com/pt-br/bpm/notacao-bpmn/>. Acesso em: 22 nov. 2019.

ORTEGA, João. Indústria 4.0: entenda o que é a quarta revolução industrial. 2019. Disponível em: <https://www.startse.com/noticia/nova-economia/60414/industria-4-0-entenda-o-que-e-quartarevolucao-industrial>. Acesso em: 19 nov. 2019.

OSCAR, Naiana. A crise na construção e você. Revista Exame, 19 mar. 2012. Disponível em: <https://exame.abril.com.br/revista-exame/a-crise-na-construcao-e-voce/>. Acesso em: 22 nov. 2019.

PAIM, Rafael; CARDOSO, Vinicius; CAULLIRAUX, Heitor; CLEMENTE, Rafael. Gestão de processos: pensar, agir e aprender. Porto Alegre: Bookman, 2009.

SILVA, Márcio Fernandes Andrade da; LAPOLLI, Édis Mafra. Aplicação do gerenciamento de processos na construção civil. 2001. Disponível em: <http://www.abepro.org.br/biblioteca/enegep2001_tr19_0547.pdf>. Acesso em: 19 nov. 2019.

SOARES, Yuri. PIB da construção civil fecha 2018 com retração de 2,5\%. 2019. Disponível em: <https://www.aecweb.com.br/revista/noticias/pib-da-construcao-civil-fecha-2018-com-retracaode-25/18503>. Acesso em: 21 nov. 2019.

TOLFO, Cristiano; MEDEIROS, Thiarles Soares; MOMBACH, Jaline Gonçalves. Modelagem de processos com BPMN em pequenas empresas: um estudo de caso. In: XXXIII ENCONTRO NACIONAL DE ENGENHARIA DE PRODUÇÃO, 2013, Salvador. Anais... Salvador: ABEPRO, 2013. p. 116. Disponível em: <http://www.abepro.org.br/biblioteca/enegep2013_TN_STO_177_013_22720.pdf>. Acesso em: 19 nov. 2019. 